\title{
Corrigendum: A Stratigraphic Approach to Inferring Depositional Ages From Detrital Geochronology Data
}

\author{
Samuel A. Johnstone ${ }^{1 *}$, Theresa M. Schwartz ${ }^{2}$ and Christopher S. Holm-Denoma ${ }^{3}$ \\ ${ }^{1}$ Geoscience and Environmental Change Science Center, U.S. Geological Survey, Denver, CO, United States, ${ }^{2}$ Department \\ of Geology and Geological Engineering, Colorado School of Mines, Golden, CO, United States, ${ }^{3}$ Geology, Geophysics, and \\ Geochemistry Science Center, U.S. Geological Survey, Denver, CO, United States
}

Keywords: detrital age, geochronology, detrital zircon, maximum depositional age, Bayesian statistics

\section{OPEN ACCESS}

Edited and reviewed by: Brian W. Romans,

Virginia Tech, United States

*Correspondence:

Samuel A. Johnstone sjohnstone@usgs.gov

Specialty section:

This article was submitted to Sedimentology, Stratigraphy and

Diagenesis,

a section of the journa

Frontiers in Earth Science

Received: 03 June 2019

Accepted: 05 June 2019

Published: 21 June 2019

Citation:

Johnstone SA, Schwartz TM and

Holm-Denoma CS (2019)

Corrigendum: A Stratigraphic

Approach to Inferring Depositional Ages From Detrital Geochronology

Data. Front. Earth Sci. 7:161

doi: 10.3389/feart.2019.00161

\section{A Corrigendum on}

A Stratigraphic Approach to Inferring Depositional Ages From Detrital Geochronology Data by Johnstone, S. A., Schwartz, T. M., and Holm-Denoma, C. S. (2019). Front. Earth Sci. 7:57. doi: 10.3389/feart.2019.00057

In the original article, there was a mistake in the published legend for Figures $\mathbf{2}$ and $\mathbf{3}$. An indexing error in the computation of the sum in Equation (7) resulted in the labels on values of $k_{c}$ being off by 1 . What was originally labeled $k_{c}=2$ should have been labeled $k_{c}=1$, what was labeled $k_{c}=3$ should have been labeled $k_{c}=2$, and so on. The corrected figures and captions appear below.

There was also an error in the text of the original article related to the above-mentioned errors in the figure legends. This impacted the text in one place. A correction has been made to section 2.2, The Search for the Youngest Grain, paragraph 5, following Equation 7:

In cases where these youngest grains make up $1 \%$ or less of all dateable minerals, we would only expect to date three of the same grains $95 \%$ of the time if we were to date around 630 grains (Figures 2 and $\mathbf{3}$ ).

The authors apologize for this error and state that this does not change the scientific conclusions of the article in any way. The original article has been updated.

Copyright () 2019 Johnstone, Schwartz and Holm-Denoma. This is an open-access article distributed under the terms of the Creative Commons Attribution License (CC BY). The use, distribution or reproduction in other forums is permitted, provided the original author(s) and the copyright owner(s) are credited and that the original publication in this journal is cited, in accordance with accepted academic practice. No use, distribution or reproduction is permitted which does not comply with these terms. 

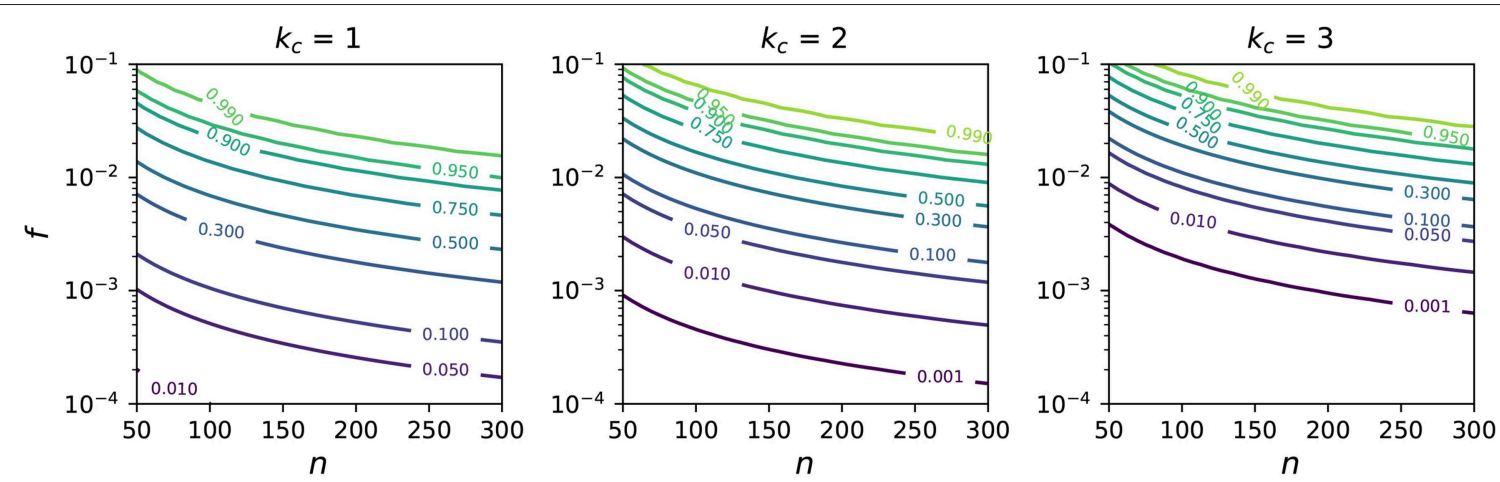

FIGURE 2 | Probabilities of dating enough grains from the youngest constituent to compute an MDA, given that $k_{c}$ grains are required to compute an MDA and that the grains belonging to the youngest age component constituents a fraction $f$ of all dateable grains (Equation 7 ). The three panels show probability contours for $k_{C}=1,2$, and 3 .

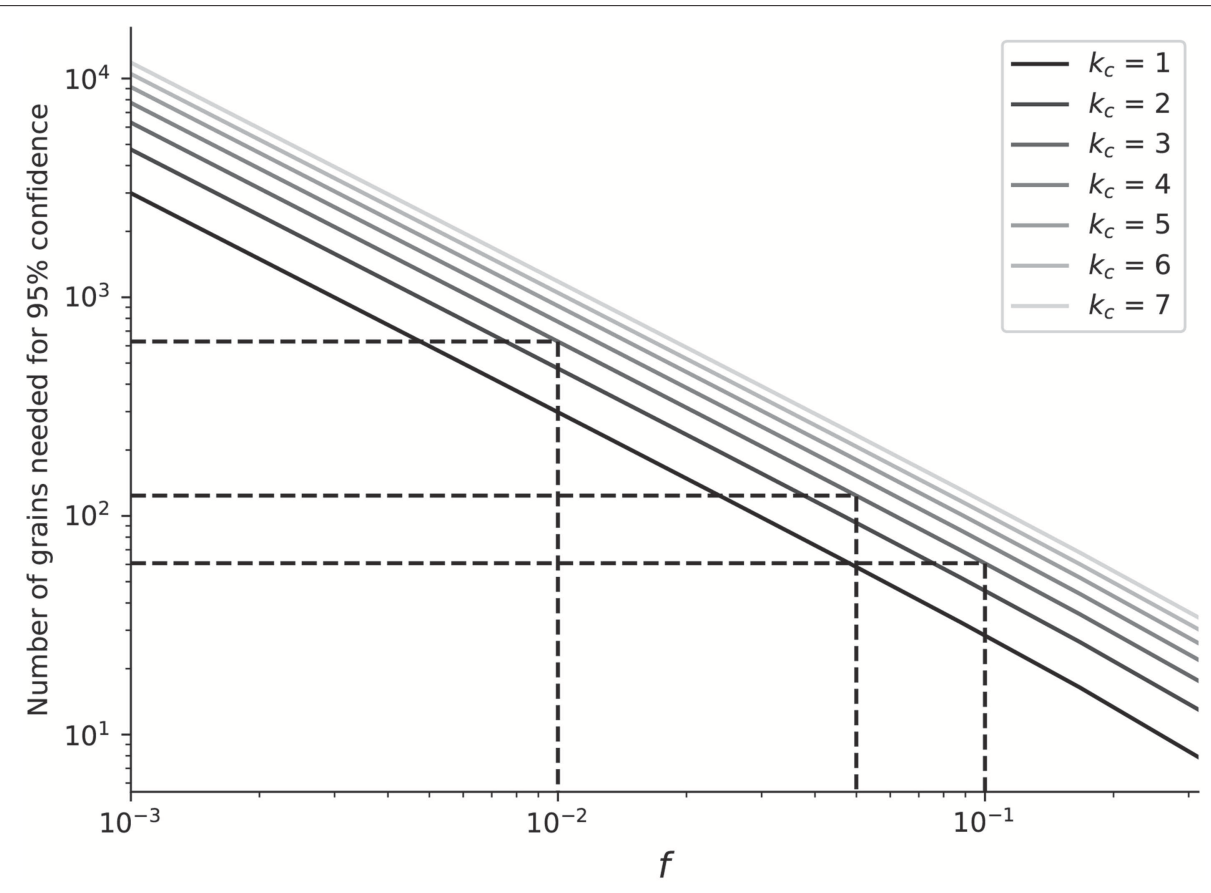

FIGURE 3 | How many grains should be dated to be $95 \%$ confident that we would date at least $k_{C}$ grains from the youngest source of grains? The solid lines provide this recommendation as a function of $f$, the fraction of dateable mineral grains from the youngest source. In practice, it is unlikely that this quantity can be known. The dashed lines represent specific recommendations for if $f=10,5$, and $1 \%$. In $95 \%$ of cases where you date $\sim 60, \sim 120$, and $\sim 630$ grains, at least 3 grains will be dated from sources that contributed 10,5 , and $1 \%$ of all the dateable minerals. 